\title{
An unusually elongated styloid process - An accidental finding
}

\author{
Beena Varma ${ }^{1}$, Krishna Santhosh Kumar ${ }^{2}$, Indu PS ${ }^{3}$, Priya KNair ${ }^{2}$,Aravind Meena Shanmugham ${ }^{4}$, Renju Jose \\ From ${ }^{1}$ Professor Emeritus, ${ }^{2}$ Assistant Professor, ${ }^{3}$ Post Graduate Student, ${ }^{4}$ Reader, ${ }^{5}$ Professor and Head, Department of Oral Medicine and Radiology, \\ Amrita School of Dentistry (Amrita Vishwa Vidyapeetham), Kochi, Kerala, India
}

A 38-year-old male patient presented with a complaint of dull aching pain in the left upper back tooth for a few weeks. The pain aggravated on having cold water and subsided on its own. The medical history, dental history, and personal history were non-contributory. On clinical examination, a retained deciduous tooth in the maxillary right back tooth region (53) was found and 26 and 44 were grossly decayed. The patient was advised to get a panoramic radiograph done. The panoramic radiograph showed impacted 13 and retained 53, periapical pathology was present in relation to 26 and 44 . The panoramic radiograph also showed an unusually elongated styloid process of length $7.6 \mathrm{~cm}$ and $0.36 \mathrm{~cm}$ width on the right side and on the left side, it had a length of $3.4 \mathrm{~cm}$ and width of $0.32 \mathrm{~cm}$ (Fig. 1). The patient was asymptomatic with regard to the elongated styloid process. The patient was advised to report back if any symptoms occur. Extraction of 26, 44, and 53 was done. Surgical extraction of impacted 13 was advised but the patient was not willing for the procedure.

The styloid process is a part of the styloid complex which also consists of styloid ligament and stylomandibular ligament. The normal length of the styloid process in adults ranges between 20 and $25 \mathrm{~mm}$. When the length of the styloid process exceeds above $30 \mathrm{~mm}$, it is considered to be elongated. Elongation of the styloid process was first described by Eagle. It is usually identified in the $3^{\text {rd }}-4^{\text {th }}$ decades of life and there is no gender predilection [1]. Due to its anatomical relation with the external, internal carotid artery, and facial nerve, it can produce pain in the neck and cervicofacial region resembling glossopharyngeal neuralgia, dysphagia, tinnitus, and otalgia which is described as Eagle's syndrome [2]. An elongated styloid process can also cause damage to the carotid artery resulting in cerebrovascular complications caused due to carotid artery dissection or thromboembolism [3]. Only $4 \%$ of patients with elongated styloid process presents with symptoms. Panoramic radiograph is the most routinely employed imaging technique for the maxillofacial region and can be used as the method for evaluation of the elongated styloid process. If

\section{Access this article online}

Received - 01 October 2021

Initial Review - 16 October 2021

Accepted - 26 October 2021

DOI: $10.32677 /$ ijcr.v7i11.3109

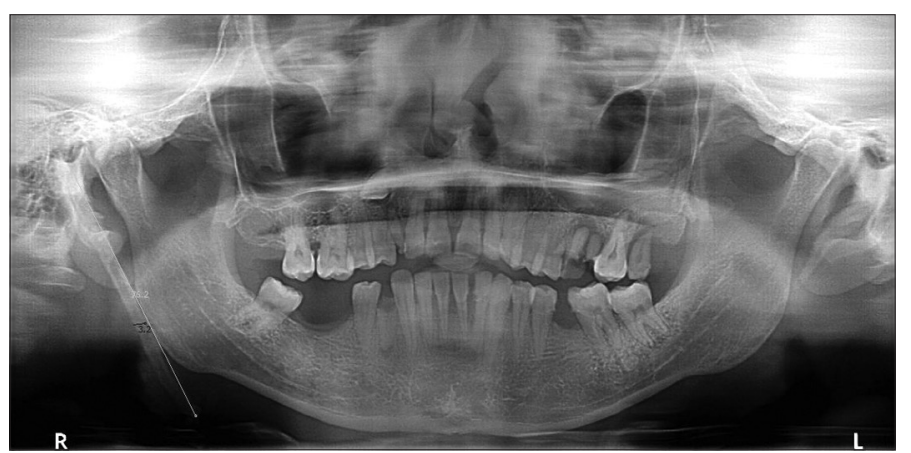

Figure 1: Panoramic radiograph showing unusually elongated styloid process of the right side

symptomatic, it can be treated conservatively using medications or surgically. If the patient is asymptomatic, no treatment is required and can be kept on regular follow-up [1].

When the styloid process is unusually elongated, one expects to find at least a few clinical signs and symptoms. This case demonstrates that even unusually large variants of normal can be asymptomatic. The elongated styloid process should always be considered in the list of differential diagnosis when the patient presents with unilateral facial pain which is not responding to other treatment measures.

\section{REFERENCES}

1. Soylu E, Altan A, Sekerci AE, Akbulut N. An asymptomatic and overelongated styloid process. Case Rep Dent 2017;2017:7971595.

2. Saccomanno S, Greco F, Corso DE, Lucidi D, Deli R, D'addona A, et al. Eagle's Syndrome, from clinical presentation to diagnosis and surgical treatment: A case report. Acta Otorhinolaryngol Ital 2018;38:166-9.

3. Ogura T, Mineharu Y, Todo K, Kohara N, Sakai N. Carotid artery dissection caused by an elongated styloid process: Three case reports and review of the literature. NMC Case Rep J 2014;2:21-5.

Funding: Nil; Conflicts of interest: Nil.

How to cite this article: Varma B, Kumar KS, Indu PS, Nair PK, Shanmugham AM, Jose R. An unusually elongated styloid process -An accidental finding. Indian J Case Reports. 2021;7(11):512.

Correspondence to: Dr. Krishna Santhosh Kumar, Department of Oral Medicine and Radiology, Amrita School of Dentistry (Amrita Vishwa Vidyapeetham), Amrita Institute of Medical Sciences, Amrita Nagar, Edappally, Kochi, Kerala, India. E-mail: krishna.santhosh32@gmail.com

(C) 2021 Creative Commons Attribution-NonCommercial 4.0 International License (CC BY-NC-ND 4.0). 